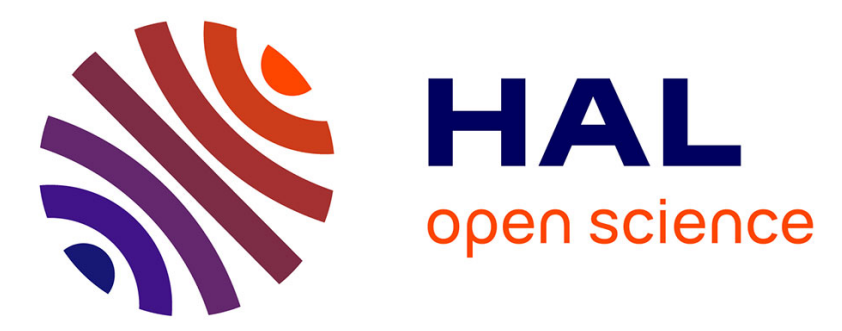

\title{
Zeolitic imidazole frameworks: structural and energetics trends compared with their zeolite analogues
}

\author{
Dewi W. Lewis, A. Rabdel Ruiz-Salvador, Ariel Gómez, L. Marleny \\ Rodriguez-Albelo, François-Xavier Coudert, Ben Slater, Anthony K \\ Cheetham, Caroline Mellot-Draznieks
}

\section{To cite this version:}

Dewi W. Lewis, A. Rabdel Ruiz-Salvador, Ariel Gómez, L. Marleny Rodriguez-Albelo, François-Xavier Coudert, et al.. Zeolitic imidazole frameworks: structural and energetics trends compared with their zeolite analogues. CrystEngComm, 2009, 11 (11), pp.2272-2276. 10.1039/B912997A . hal-02142934

\section{HAL Id: hal-02142934 \\ https://hal.science/hal-02142934}

Submitted on 29 May 2019

HAL is a multi-disciplinary open access archive for the deposit and dissemination of scientific research documents, whether they are published or not. The documents may come from teaching and research institutions in France or abroad, or from public or private research centers.
L'archive ouverte pluridisciplinaire HAL, est destinée au dépôt et à la diffusion de documents scientifiques de niveau recherche, publiés ou non, émanant des établissements d'enseignement et de recherche français ou étrangers, des laboratoires publics ou privés. 


\title{
Zeolitic Imidazole Frameworks: Structural and Energetics Trends compared with their Zeolite Analogues
}

\author{
Dewi W. Lewis, ${ }^{a}$ A. Rabdel Ruiz-Salvador, ${ }^{b}$ Ariel Gómez, ${ }^{c}$ L. Marleny Rodriguez-Albelo,${ }^{b}$ François- \\ Xavier Coudert, ${ }^{a}$ Ben Slater, ${ }^{a}$ Anthony K. Cheetham ${ }^{d}$ and Caroline Mellot-Draznieks ${ }^{a, *}$
}

DFT calculations suggest many nanoporous Zinc Imidazole Frameworks (ZIFs) are viable synthesis targets and reveal a 10 more complex energy landscape than their zeolite counterparts.

Zeotypes are technologically important nanoporous inorganic materials with more than 180 topologies known to date. ${ }^{1}$ In addition to the aluminosilicate zeolites, many other zeolitelike inorganic materials were discovered in the 1980s and $90 \mathrm{~s}$,

15 such as the aluminium and transition metal phosphates. ${ }^{2}$ More recently, during the last decade, intensive efforts have been made to develop a new class of zeolitic structures based upon hybrid metal-organic framework materials (MOFs). Such work is driven by the prospect of expanding pore sizes,

20 enhancing their functionality, and finding new sorption and catalytic properties. ${ }^{3}$ A number of zeolitic architectures have been successfully synthesised as hybrid frameworks, either fortuitously ${ }^{4}$ or rationally. ${ }^{5}$ Among them are the zeolitic imidazole frameworks (ZIFs). ${ }^{6}$ ZIFs adopt crystalline 25 architectures, where typically $\mathrm{Zn}^{2+}$ ions play the role of silicon and the imidazolate anions form bridges that mimic the role of oxygen in zeolites (Figure 1). Currently about 20 distinct ZIFs have been synthesised, a subset of which possess the same framework topology as zeolites. Most of the known ${ }_{30} \mathrm{ZIFs}$ contain $\mathrm{Zn}$ or $\mathrm{Co}$ ions in combination with imidazolate or functionalized imidazolate anions. ${ }^{6}$ However, the factors that determine which zeolite topologies will form as ZIFs, and which will not, have yet to be elucidated.

Computer simulations have been widely used in the zeolite 35 area, for example in predicting their structures ${ }^{7}$ and in determining adsorption properties. $^{8}$ More recently, simulations have begun to play a role in the area of MOFs. ${ }^{9}$ In the case of ZIFs, first principles calculations based upon density functional theory (DFT) were successfully used to 40 explore hypothetical ZIFs with dense topologies. ${ }^{10}$

The recent synthesis of ZIF-20 $0^{[6 \mathrm{~d}]}$ which has the LTA topology suggests that other very large pore ZIFs might be viable. Thus, here, we utilise DFT methods to estimate the relative energies of a range of large pore hypothetical ZIFs

a Department of Chemistry, University College London, 20 Gordon St., London, WC1H 0AJ, UK. E-mail: c.mellot-draznieks@ucl.ac.uk

${ }^{b}$ Zeolite Engineering Laboratory, Institute of Science and Technology of Materials (IMRE) -Faculty of Physics, University of Havana, Havana, 10400, Cuba. ${ }^{c}$ Dept. Physics, MacNaughton Building, Gordon Street, University of Guelph, Guelph, Ontario, Canada NIG 2WI

${ }^{d}$ Department of Materials Science and Metallurgy, University of Cambridge, Pembroke Street, Cambridge, CB2 3QZ, UK.

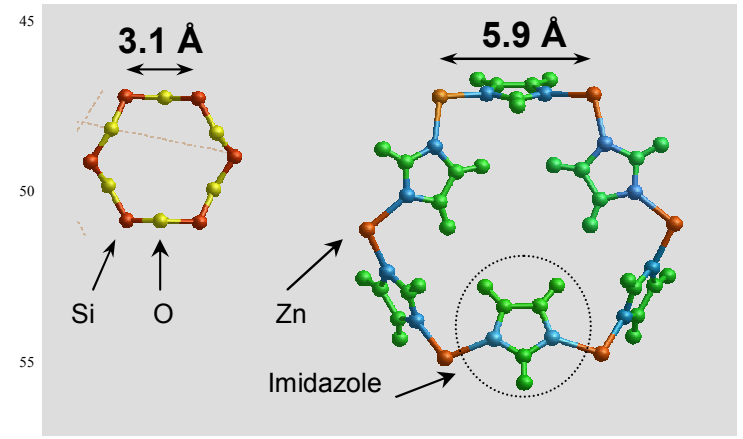

Fig1 Zeolites versus ZIFs: the sequence of Si-O-Si bonds in zeolites (left) and of Zn-IM-Zn in ZIFs (right) is compared for a 6-ring. 60

such as FAU- and LTL-, together with those of known ZIFs including porous and dense structures. Taking a selection of $\sim 10$ zeolite topologies extracted from the existing IZA database of zeolite structures ${ }^{1}$ and converting these topologies ${ }_{65}$ to ZIFs, we consider the structure and stability of these materials. The results shed light on the factors that control the structural diversity of this interesting new class of materials.

In the first stage of our calculations, we constructed starting models of ZIFs with the $\mathrm{Zn}$ (IM) ${ }_{2}$ chemical composition. The 70 crystallographic data of known ZIFs were retrieved from the CCDC, eliminating the imidazole substituents when required. In total, three structures with dense topologies, i.e. cag- (ZIF$4),{ }^{6 \mathrm{c}}$ crb- (ZIF-1), ${ }^{6 \mathrm{a}} \mathrm{zni}_{-},{ }^{11}$ and eight known structural analogues of zeolites, i.e. BCT- (ZIF-2), ${ }^{6 c}$ DFT- (ZIF-3), ${ }^{6 c}$ ${ }_{75}$ GIS- (ZIF-6), ${ }^{6 c}$ SOD (ZIF-7, ZIF-8, ZIF-9), ${ }^{6 c}$ MER- (ZIF$10),{ }^{6 c}$ and LTA (ZIF-20), ${ }^{6 d}$ were considered. In view of the very large choice of topologies from the IZA database, ${ }^{1}$ only a selection of hypothetical zeolite types was explored. They are listed in Table S1, described by their three-letter IZA codes. ${ }_{80}$ Our choice of zeolite topologies was guided by the intriguing fact that all ZIFs synthesised to date possess uninodal nets. Having this in mind, we chose to construct hypothetical ZIFs possessing both uninodal - ACO, ABW, AFI, ATN, ATO, CAN - and multimodal nets - LTL and AST (both 2 nodes), 85 and FER (4 nodes). We also considered, despite its very large cell volume $\left(\sim 26,000 \AA^{3}\right)$, the uninodal FAU-type model due to its remarkable low density and its hierarchical system of pores. For each framework topology, we applied the code TOBUNPOROUS, ${ }^{12}$ which replaces the tetrahedra with the ${ }_{90}$ given metal ion and bridging ligand (See SI). 


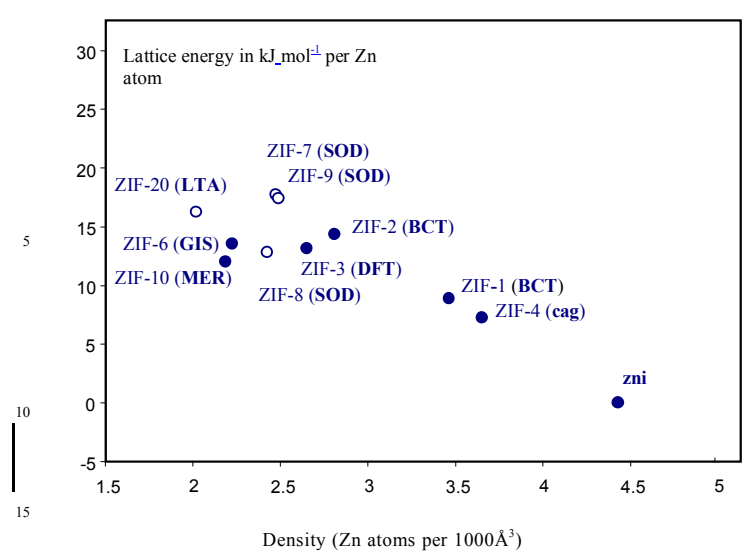

Fig. 2 Variation of calculated lattice energy of the known ZIFs with their framework density, expressed as the number of $\mathrm{Zn}$ sites per volume unit. (•) pure imidazole ZIFs, (o) substituted imidazole ZIFs.

In the second stage of the work, we performed energy minimisation calculations to determine the equilibrium structures and the relative lattice energies of both the experimentally determined and hypothetical models using ${ }_{25}$ DFT methods, with the aim of identifying new and viable ZIFs topologies. Our choice of DFT method is dictated and constrainted firstly by the absence of flexible validated force fields for hybrid materials, but secondly by the large unit cells considered here. DFT methods have proved to be efficient in 30 addressing the energetics and structures of hybrid compounds, ${ }^{10,13}$ but plane-wave methods are too expensive for the unit cells considered here. Thus, DFT calculations were carried out with the code SIESTA, which uses atom centered basis functions that are more efficient (than plane waves) for 35 total energy studies of very low density materials. ${ }^{14}$ Energies of all structures in their primitive cells or unit cells were minimized by geometry optimization at constant pressure using the GGA PBE functional, where both cell parameters and atomic coordinates were relaxed. Further details on the 40 calculations and the energy minimized ZIFs are reported in SI.

It is important to emphasize that the energy-minimized structures of all the known ZIFs are in excellent agreement with the experimental data (see SI), underlining the robustness of the energy minimizations. Figure 2 plots the calculated ${ }_{45}$ lattice energies of our set of known ZIFs structures as a function of their framework densities, expressed as the number of $\mathrm{Zn}$ sites per volume unit. The energy for each structure was normalized relative to the number of $\mathrm{Zn}$ atoms in the unit-cell and compared to the normalized lattice energy 50 of the most stable dense polymorph, zni- ${ }^{11}$ taken here as the reference structure. We have computed 8 known topologies in their pure imidazole forms, though some have only been prepared with substituted imidazolate anions. For example, the LTA topology is shown with the unsubstituted imidazole ${ }_{55} \mathrm{Zn}(\mathrm{IM})_{2}$ composition, although it has only been synthesized as ZIF-20 with purine. Similarly, our pure imidazole $\left(\mathrm{Zn}(\mathrm{IM})_{2}\right)$ models of the sodalite ZIFs (ZIF-7, ZIF-8 and ZIF-9) are simplifications of the real materials due to our neglect of substituants on the imidazole ring $\left(-\mathrm{CH}_{3},-\mathrm{C}_{6} \mathrm{H}_{4}\right)$.

60 To a reasonable approximation, it appears that two distinct groups of materials can be identified among the known

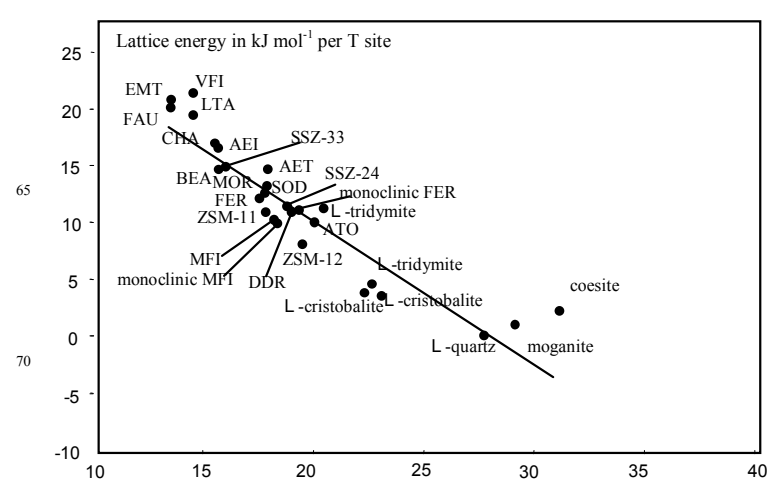

75 Density (T atoms per $1000 \AA^{3}$ )

Fig. 3 Calculated lattice energy of the $\mathrm{SiO}_{2}$ zeolites with their framework density. Reproduced by permission of ref (15). Copyright American Chemical Society 1994.

80 structure types: a first group consisting of ZIFs synthesized with pure imidazole correspond to the most stable topologies (ZIF-1-2-3-4-6-10), and a second group of slightly less stable ZIFs, which are those experimentally only obtained with substituted imidazole (ZIF-7-9-20). ZIF-8, made with a 85 substituted ligand, is the only exception to this grouping. This finding would suggest that certain architectures can be stabilized due to the interactions between the substituents on the imidazole ligands.

The variation in the lattice energy of the three SOD 90 structures $(Z I F-7,-8 .-9)$ of $12-17.5 \mathrm{~kJ}^{-\mathrm{mol}^{-1}}$ range is illustrative of the impact of the ligand on the stabilisation of a given topology. The relative orientation of the imidazole molecules within the 6-rings is very different in ZIF-7 and -9 than in ZIF-8 where a regular "up" and "down" orientation is 95 observed. While the latter is highly symmetrical and is the most stable one, the simulations reveal that the use of substituted imidazole in ZIF-7 and -9 allows the synthesis of metastable and distorted SOD structures (see SI), where the energetic cost of cooperative framework distortions may be 100 compensated by stabilizing interactions between substituents.

One striking feature of the simulations is that there is a rather restricted variation of lattice energies for the known ZIF architectures, with less than $18 \mathrm{~kJ} \mathrm{~mol}^{-1}$ separating the most stable structure (zni) from the least stable (ZIF-7-SOD). 105 It is also noteworthy that the more dense structures found experimentally are the most stable ones, with the dense zni and cag- lying in the lower part of the energy/density plot. There is an approximately linear trend of lattice energies with density. Indeed, the variation in relative lattice energies of 110 both the ZIFs and siliceous zeolites is remarkably, if coincidentally, similar, particularly given the approximate 10 fold difference in density. (Figure 3). ${ }^{15}$ It is probable that the stabilisation of dense ZIF structures relative to more open ones might be even more pronounced than our calculations 115 would suggest because the DFT method neglects the van der Waals interactions.

In Figure 4 we compare the energies of the hypothetical ZIF structures (in red) with those of the known architectures (in blue). While the energies of the hypothetical structures are 


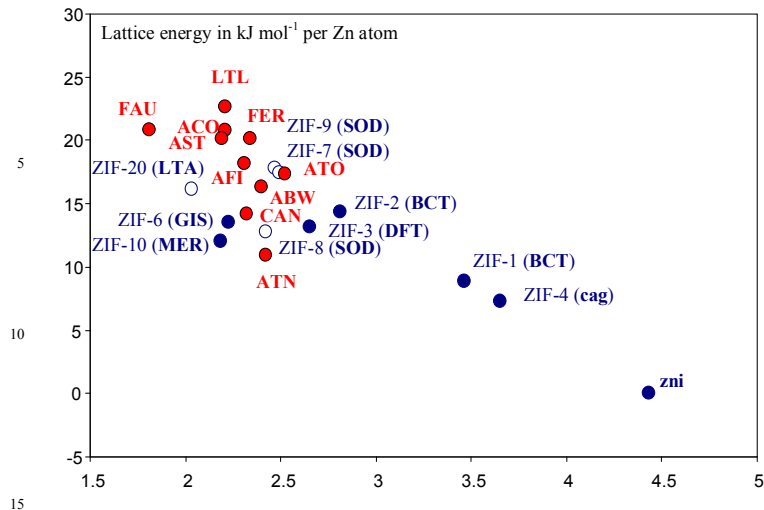

15

Density ( $\mathrm{Zn}$ atoms per $\left.\mathrm{nm}^{3}\right)$

Fig. 4. Calculated lattice energies of hypothetical ZIF structures (red) compared to those of known ZIFs (blue).

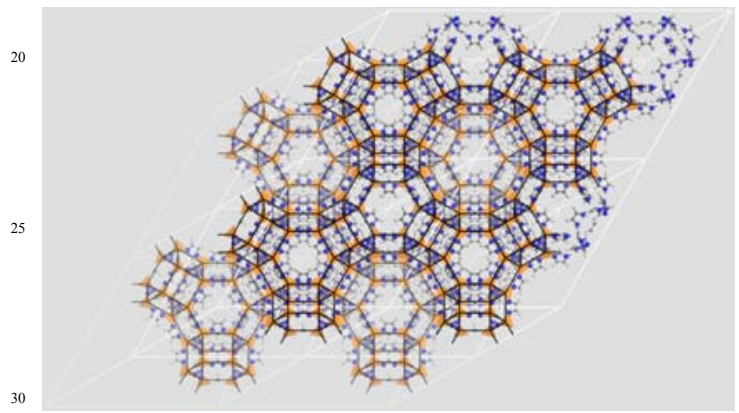

Figure 5. Simulated crystal structure of the FAU-type ZIF (N: blue, $\mathrm{C}$ : grey, $\mathrm{H}$ : white, and $\mathrm{Zn}$ :orange tetrahedra).

generally higher than the known ones, the difference is not 35 very great in several cases and we conclude that a number of other topologies should be accessible experimentally, even with unsubstituted imidazolates. This is especially the case for the two topologies, CAN and ATN, whose lattice energies fall within the range of the already synthesised structures. Indeed, ${ }_{40}$ ATN is among the most stable structures considered, with a lattice energy similar to that of the imidazole-containing ZIF2 (BTC) and ZIF-10 (MER). The other hypothetical ZIFs, including the very large pore FAU (Figure 5) and LTL-type ZIFs, together with AST, ACO and AFI, have less favourable 45 relative lattice energies. Nevertheless, as with zeolites, these lower density frameworks may be experimentally accessible through the modifications of the framework compositions, using here substituted ligands. In ZIFs, the substituted ligand can act as a secondary structure directing agent, as illustrated 50 by the $\sim 5 \mathrm{~kJ} \mathrm{~mol}^{-1}$ difference between $\mathrm{ZIF}-7$ and -8 which both possess the SOD topology. The very recent synthesis of the ACO topology ${ }^{16}$ with a mixture of 5-methylbenzimidazole and imidazole supports the above conclusions.

The fact that several ZIF structures have almost the same ${ }_{55}$ framework lattice energy shows clearly that kinetic control must be important for the crystallization of these systems, as with zeolites. Equally, the fact that the less stable systems have not been synthesised indicates that thermodynamic considerations are important too. Nevertheless, we expect that 60 strategies to stabilise the framework such as substitution on the ligand or "templating" may be applicable and provide routes to the less stable topologies. At this stage, we do not fully understand the synthetic factors that control this delicate balance. However, there is no doubt that a number of hitherto 65 undiscovered topologies should be amenable to synthesis and that even the most open framework types might be obtained with appropriately substituted ligands. Furthermore, the possibility of discovering not-yet-synthesized zeolitic topologies remains very real, as exemplified by the fact that 70 the most stable of all the ZIFs, zni, has a topology that is unknown as a silica polymorph, though it is known as the dense aluminosilicate, banalsite $\mathrm{BaSi}_{2} \mathrm{Al}_{2} \mathrm{O}_{8} \cdot{ }^{17}$

\section{Notes and references}

\$ C.M.D. thanks the EPSRC for an Advanced Research Fellowship. 75 Computer resources on the $\mathrm{HPC} x$ service were provided via our membership of the UK's HPC Materials Chemistry Consortium and funded by EPSRC (portfolio grant EP/D504872). AKC thanks the European Research Council for an Advanced Investigator Award. ARRS thank CITMA PNCyT Progam on Basic Sciences (Cuba) and the EU 80 ALFA network for the Nanogastor project II-0493-FA-FI.

1 http://www.iza-structure.org/databases.

2 A.K. Cheetham, G. Férey, and T. Loiseau, Angew. Chem. Int. Ed. 1999, 38, 6296.

3 (a) A.K. Cheetham, C.N.R. Rao, R. K. Feller, Chem. Comm. 2006,

85 46, 4780. (b) G. Férey, C. Mellot-Draznieks, C. Serre, F. Millange, Acc. Chem. Res. 2005, 38, 217. (c) P.M. Forster, A.K. Cheetham, Topics in Catal. 2003, 24, 79.

4 (a) G. Férey, C. Serre, C. Mellot-Draznieks, F. Millange, S. Surblé, J. Dutour, I. Margiolaki, Angew. Chem. Int. Ed. 2004, 43, 6296. (b) G.

90 Férey, C. Mellot-Draznieks, C. Serre, F. Millange, J. Dutour, S. Surblé, I. Margiolaki, Science 2005, 309, 2040. (c) Q. R. Fang, G. S. Zhu, J. Y. Sun, Y. Wei, S. L. Qiu and R. R. Xu, Angew. Chem., Int. Ed. 2005, 44, 3845. (d) Q. R. Fang, G. S. Zhu, M. Xue, J. Y. Sun and S. L. Qiu, Dalton Trans., 2006, 2399.

955 (a) Y. L. Liu, V. C. Kravtsov, R. Larsen and M. Eddaoudi, Chem. Commun. 2006, 1488. (b) X. C. Huang, Y.Y. Lin, J. P. Zhang, X. M. Chen, Angew. Chem. Int. Ed. 2006, 45, 1557.

6 (a) Y.Q. Tian, C.X. Cai, X.M. Ren, C. Y. Duan, Y. Xu, S. Gao, X. Z. You, Chem. Eur. J. 2003, 9, 5673. (b) G. H. Cui, J. R. Li, J. L. Tian, 100 X. H. Bu, S. R. Batten, Crystal Growth Design 2005, 5, 1775. (c) K. S. Park, Z. Ni, A. P. Côté, J. Y. Choi, R. D. Huang, F. J. UribeRomo, H. K. Chae, M. O'Keeffe and O. M. Yaghi, Proc. Natl. Acad. Sci. U. S. A. 2006, 103, 10186. (d) H. Hayashi, A. P. Côté, H. Furukawa, M. O'Keeffe, O. M. Yaghi Nature Materials 2007, 6, 501.

105 (e) R. Banerjee, A. Phan, B. Wang, C. Knobler, H. Furukawa, M. O'Keeffe, O. M. Yaghi, Science 2008, 319, 939. (f) B. Wang, A. P. Côté, H. Furukawa, M. O'Keeffe, O.M. Yaghi Nature 2008, 453, 20.

7 S. M. Woodley, R. Catlow Nature Materials 2008, 7, 937.

8 A. H. Fuchs, A. K. Cheetham, J. Phys. Chem. B. 2001, 105, 7375.

1109 C. Mellot-Draznieks, J. Mater. Chem. 2007, 17, 4348.

10 I. A. Baburin, S. Leoni, G. Seifert J. Phys. Chem. 2008, 112, 9437.

11 R. Lehnert, F. Seel, Z. Anorg. Allg. Chem. 1980, 464, 187.

12 A. R. Ruiz-Salvador, A. Gomez, D. W. Lewis, C. Mellot-Draznieks, and L. M. Rodriguez-Albelo, TOBUNPOROUS: TOpological BUilding of NanoPOROUs Solids, in preparation.

13 (a) H. G. Harvey, B. Slater, M. P. Attfield, Chem.-Eur. J. 2004, 10, 3270. (b) C. Lee, C. Mellot-Draznieks, B. Slater, G. Wu, W. T. A. Harrison, C. N. R. Rao, A. K. Cheetham, Chem. Comm. 2006, 2687.

14 J.M. Soler, E. Artacho, J. D. Gale, A. Garcia, J. Junquera, P. Ordejon, D. Sanchez-Portal, J. Phys.: Condens. Matter 2002, 14, 2745.

15 N. Henson, A. K. Cheetham, J. D. Gale, Chem. Mater. 1994, 6, 1647.

16 T. Wu, X. H. Bu, J. Zhang, P. Y. Feng, Chem. Mater. 2008, 20, 7377.

17 Takeuchi, Y. Kudoh, N. Haga, Zeitschrift. Kristall. 1973, 138, 313. 